\title{
De første levertransplantasjonene i Norge og veien dit
}

\begin{abstract}
Selv om nyretransplantasjon var et reelt tilbud i Norge fra 1969, ble organtransplantasjoner stort sett betraktet som eksperimentell medisin fra dets begynnelse tidlig i 1950-årene og frem til registreringen av ciklosporin i 1982. Etter den første vellykkede nyretransplantasjonen i 1954 gikk det 13 år før hjerte og lever ble vellykket transplantert, begge i 1967.

Inspirert av foregangsmennene Thomas Starzl i Denver og Roy Yorke Calne i Cambridge begynte Snorre Aune, Gunnar Schistad og Andreas Skulberg tidlig i 1968 eksperimentelle studier på gris på Ullevål sykehus for å utvikle en kirurgisk teknikk for levertransplantasjon. De samarbeidet med et team på Rikshospitalet ledet av Audun Flatmark og transplanterte annenhver uke der og annenhver uke på Ullevål. Det tok over ett år med ukentlige dyreforsøk før den første transplanterte grisen overlevde. De tre første levertransplantasjonene på mennesker ble så gjort på 2. avdeling, Ullevål sykehus i 1969, 1970 og i 1972. Den første pasienten døde kort etter avsluttet operasjon, den andre etter 24 dager og den tredje 53 dager etter transplantasjonen. For dette pionerarbeid fikk Snorre Aune, Gunnar Schistad og Andreas Skulberg Michael Skjelderups gullmedalje i 1971.
\end{abstract}

Denne artikkelen bygger på egne opplevelser som assistentlege og juniorpartner ved de dyreeksperimentelle forsøkene og de første levertransplantasjonene på menneske i Norge samt på en gjennomgang av relevante publikasjoner.

I perioden 1951-53 ble det på Harvard og Peter Bent Brigham Hospital i Boston, USA gjort ni homotransplantasjoner av nyre på mennesker, tre med levende ubeslektede givere og seks med nyre fra avdøde. Fire av nyrene produserte urin 37-180 dager før de ble avstøtt. Alle pasientene døde. I sin rapport konkluderte David Hume (1917-73) og medarbeidere med at «nyre-homotransplantasjon på menneske har ingen terapeutisk plass i dagens medisin» (1).

I 1954 gjorde Joseph Murray (1919-2012) ved Peter Bent Brigham Hospital nyretransplantasjon mellom to eneggede tvillinger (2). Mottaker levde $\mathrm{i}$ åtte år postoperativt, og dette blir gjerne regnet som den første vellykkede organtransplantasjonen i verden. Det var den første som hadde positiv innvirkning på pasientens livsløp. Joseph Murray fikk i 1990 Nobelprisen i medisin, blant annet for dette.

Erik Thorsby (f. 1938) nevner i sin artikkel om norsk transplantasjonsmedisin gjennom 50 år at Leif Efskind (1904-87) gjorde Norges og Skandinavias første nyretransplantasjon allerede i 1956. Denne pasienten levde i 30 dager med nyre fra ubeslektet donor (3).

I 1963 ble den første vellykkede nyretransplantasjonen i Norge gjort på 3. avdeling, Ullevål sykehus. Under ledelse av Carl Semb (1895-1971) kom Richard Wilson fra Peter Bent Brigham Hospital og satte inn en nyre som ble hentet fra pasientens mor. Denne pasienten levde i 22 år med den godt fungerende transplanterte nyren (3).

I 1967 utførte Thomas Starzl (f. 1926)
Ved University of Colorado, Denver, USA den første vellykkede levertransplantasjonen på en halvannet år gammel pike, samme år som Christiaan Barnard (1922-2001) gjorde den første hjertetransplantasjonen i Sør-Afrika. Pasienten til Barnard døde etter 18 dager, Starzls pasient levde i over 13 måneder $(4,5)$. Barnard selv uttrykte forbauselse over at han fikk så mye oppmerksomhet. Han fikk audiens både hos paven og president Carter. I 1968 gjorde Roy Yorke Calne (f. 1930) ved Cambridge University i England den første vellykkede levertransplantasjonen i Europa (6). Verken Starzl eller Calne fikk særlig oppmerksomhet da, men er senere blitt hyllet som levertransplantasjonens «fedre».

Levertransplantasjonsforsøk på dyr I 1968 var Snorre Aune (f. 1925) og Gunnar Schistad (1926-2014) begge reserveleger på 2. avdeling, Ullevål sykehus, og Andreas Skulberg (f. 1924) var overlege på anestesiavdelingen. De fant sammen ut at de ville utvikle en kirurgisk teknikk for levertransplantasjon. De startet eksperimentering med levertransplantasjon på dyr i samarbeid med et team ledet av Audun Flatmark (1926-2004) på Rikshospitalet. Han hadde vært i Denver hos Thomas Starzl og var inspirert av ham. De hadde også et nært samarbeid med et team i Göteborg, ledet av Stig Bengmark (f. 1929), som også arbeidet med å utvikle en teknikk for levertransplantasjon på dyr. Morten Ræder (1939-2012) og jeg var på det tidspunktet assistentleger

\section{Mons Lie}

mons.lie@online.no

Oslo

Engelsk oversettelse på www.tidsskriftet.no 


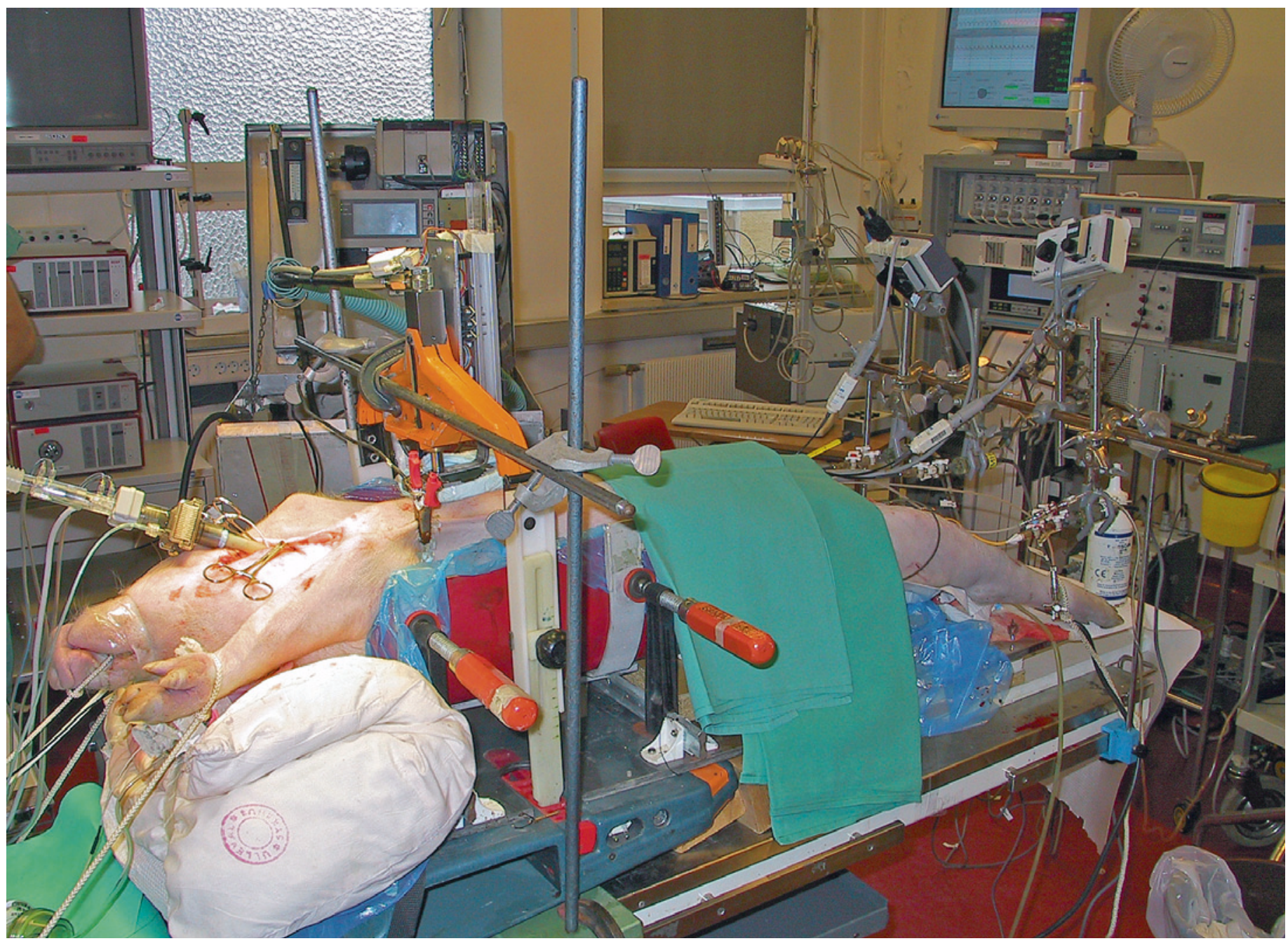

Gris på operasjonsbordet, Institutt for eksperimentell medisinsk forskning, Ullevål universitetssykehus, ca. år 2000. Det er den samme operasjonsstuen som ble brukt av oss 30 år tidligere. Foto: Roy Trondsen

på 2. avdeling, Ullevål sykehus. Vi var helt i begynnelsen av vår kirurgiske utdanning og var med som juniorpartnere i det eksperimentelle og kliniske arbeidet med levertransplantasjonene helt fra starten.

Tidlig på året 1968 begynte vi med å transplantere en dag i uken. Annenhver uke var vi på Rikshospitalet, på institutt for kirurgisk forskning, der teamet fra Ullevål tok ut lever på hund og teamet fra Rikshospitalet satte inn. Annenhver uke var vi på forskningsinstituttet på Ullevål, der rikshospitalteamet tok ut og vi satte inn lever på gris. Audun Flatmark brukte en heterotop teknikk, dvs. satte inn ny lever ektopisk uten å ta ut resipientens lever. Snorre Aune brukte en ortotop teknikk, der resipientens lever ble tatt ut og den nye satt inn anatomisk (5). Dagen før vi skulle transplantere hentet Morten Ræder og jeg to griser på rundt $20 \mathrm{~kg}$ på slakteriet på Slemmestad, med en liten varebil som Forskningsinstituttet på Ullevål eide. De var i instituttets dyrestall om natten og ble anestesert neste dag av dyrepasser Ove Moen (f. 1942) og Andreas Skulberg. Vi hentet også griseblod på slakteriet. Innsetting av lever ble gjort av Snorre Aune, assistert av Gunnar Schistad, Morten Ræder og meg. Anestesien ble tatt hånd om av Andreas Skulberg. Alle grisene døde, så vel giver som mottaker. Ræder og jeg slaktet alle de døde grisene oppe på dyrestallen, flådde og parterte utover kvelden. Vi fordelte kjøttet mellom teamets medlemmer og de på forskningsinstituttet som var interessert. Det var unge velsmakende dyr som var populære blant mange.

Også på Rikshospitalet døde alle hundene. Snorre Aune og Gunnar Schistad var begge dyktige generelle kirurger, og dette var den gang svært krevende kirurgi rent teknisk. Problemene besto i å korte ned iskemitid for transplantatet og å takle den venøse stuvningen når vena cava og portvenen ble avklemt ved uttak av mottakers lever. Dette gjorde den ortotopiske tek- nikken vanskeligere enn den heterotope. Anastomosene og blødningsproblemene ga betydelige tekniske utfordringer.

Vi hadde en rekke møter med Stig Bengmark og teamet i Göteborg, som i likhet med oss på Ullevål brukte ortotop innsetting. Også deres griser døde. Den eneste som vi kjente til i Europa som fikk transplanterte griser til å overleve, var Roy Calne i Cambridge.

\section{Griseleverperfusjon}

Høsten 1968 ble en kvinne i begynnelsen av 20-årene innlagt på Rikshospitalet med anemi, ødemer, ascites samt orale og perianale ulcerasjoner. Hun hadde siden tidlig ungdomstid blitt behandlet for diaré og rektalblødninger og hadde aldri hatt menstruasjon. To dager etter innleggelsen fikk hun svær rektalblødning og gikk i sjokk. Det viste seg at hun hadde en ulcerøs kolitt med stor knudrete lever og betydelig forstørret milt. Hun ble kolektomert og var relativt 


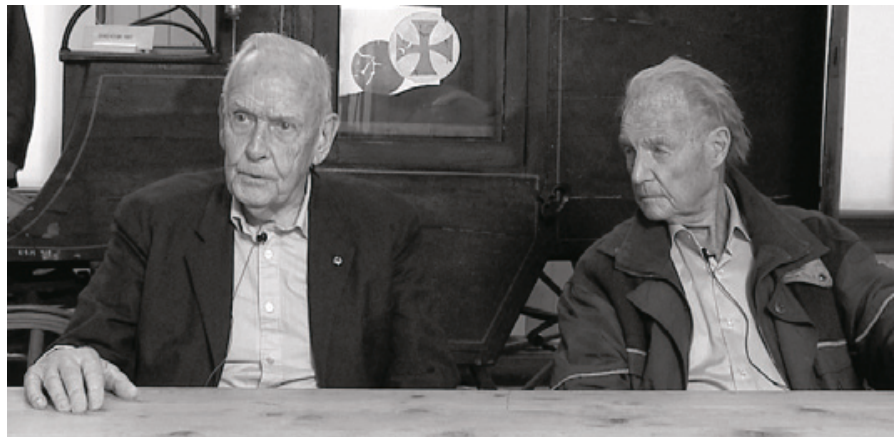

Andreas Skulberg (venstre) og Gunnar Schistad. Skjermbilde fra videointervju gjengitt med tillatelse (17). Foto: Kåre Eide

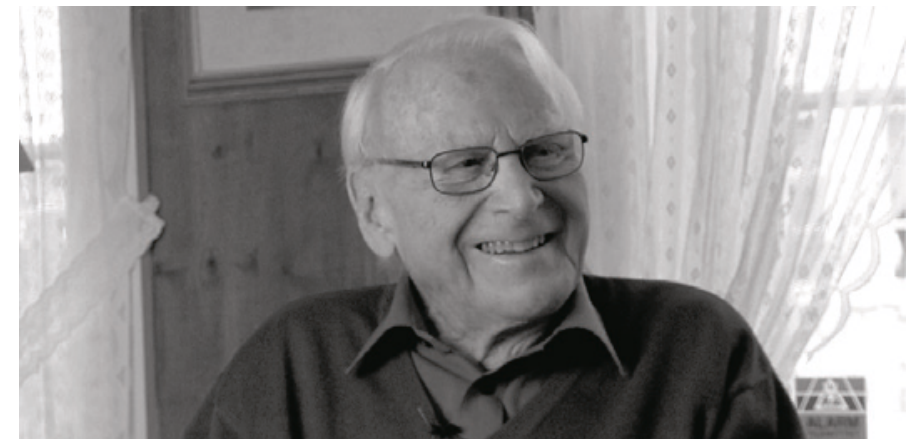

Snorre Aune. Skjermbilde fra videointervju, gjengitt med tillatelse (17) Foto: Kåre Eide kjekk i ett døgn, før hun fikk hematemese fra oesophagusvaricer. Blødningen ble stanset med Sengstaken-Blakemore-sonde, men dagen etter gikk hun i leverkoma.

Vi hadde på det tidspunktet ikke klart å få transplanterte griser eller hunder til å overleve, slik at ingen tenkte på å levertransplantere denne pasienten. Derimot hadde vi stor erfaring i å ta ut og preservere griselever. Både fra USA og England var det kommet rapporter om vellykkede behandlinger av akutt leverkoma med ekstrakorporal, heterolog leverperfusjon (7). Selv om disse behandlingene var av eksperimentell art, besluttet Flatmark og hans team, sammen med Aune, Schistad og Skulberg å gjøre et forsøk på denne pasienten. Morten Ræder og jeg hentet gris på Slemmestad, leveren ble tatt ut på Rikshospitalet og lagt i en steril pose med saltvann i et vannbad på $38^{\circ} \mathrm{C}$. Etter tre minutters iskemitid ble leveren perfundert i 14 minutter med $2500 \mathrm{ml}$ væske til levereffluatet var helt klart uten tegn til blod. Leveren ble så perfundert med pasientens arterielle blod fra kanylering av begge femorale arterier til arteria hepatica og vena porta. Veneblodet ble ført tilbake til pasientens vena saphena magna ved hjelp av en pulserende pumpe. Leverperfusjonen varte i fire timer. Etter tre kvarter begynte galleproduksjon, som i løpet av de neste $31 / 2$ timene var $90 \mathrm{ml}$. Ammoniakk i pasientens arterielle blod falt fra $160 \mu \mathrm{g} / 1$ til 59 $\mu \mathrm{g} / \mathrm{l}, \mathrm{og}$ bilirubin fra $10,8 \mathrm{mg} / \mathrm{ml}$ til $6 \mathrm{mg} /$ $\mathrm{ml}$. Neste morgen reagerte pasienten på tiltale, men var ikke helt våken. Utover dagen ble hun tiltakende komatøs. Samme kveld ble det gjort ny leverperfusjon. Denne perfusjonen var ikke vellykket. Leveren svulmet opp, var biokjemisk mye mindre effektiv og pasientens blodtrykk svingte som tegn på pågående blødning. Blødningen var etter hvert ute av kontroll og hun døde neste dag.

Rapporten om dette tilfellet, som ble publisert i Tidsskriftet, konkluderte med: «Vi planlegger å fortsette med dette behandlingsopplegget $\mathrm{i}$ egnede tilfeller, akutt hepatitt og toksisk leverskade, og kan tilby behandlings- opplegget for andre sykehus som får slike pasienter innlagt.» (8). Så vidt jeg vet, ble behandlingen ikke gjentatt i Norge og er altså eneste gang heterolog griseleverperfusjon har vært forsøkt her i landet.

\section{Besøk av Roy Calne}

Vi fortsatte ufortrødent å transplantere. Grisene på Ullevål og hundene på Rikshospitalet døde alle. Heller ikke Stig Bengmark fikk det til. Utpå nyåret 1969 tok vi kontakt med Roy Calne i Cambridge, og han kom til Ullevål. Han var en sympatisk, stillfaren mann, og ble senere adlet for sin innsats innenfor transplantasjonskirurgien. Han sto hele dagen på forskningsinstituttet på Ullevål og så på oss transplantere lever på gris og at grisen døde kort etter avsluttet operasjon. Så sa han: «Dere gjør alt riktig. Bare fortsett, og så skal dere se at en dag făr dere plutselig grisen til å overleve, uten at dere vet hva dere har gjort annerledes. Etter det kommer alle grisene til å overleve. Dette har jeg selv erfart». Deretter ble han med hjem og spiste middag sammen med Ræder og meg før vi kjørte ham til flyplassen. Jeg vet ikke, men det skulle ikke forbause meg om han betalte billetten på turistklasse selv. Det han sa stemte. Kort tid senere overlevde plutselig grisen, og etter det, hver eneste gris vi transplanterte. Grisene levde og trivdes med transplantert lever til de måtte avlives av plasshensyn. Vi hadde fått det til. Vi verifiserte det andre hadde rapportert tidligere, at avstøtning av griselever var mild sammenliknet med det man fant hos hund (9).

\section{Levertransplantasjoner på menneske}

Sommeren 1969 ble den første levertransplantasjonen på menneske i Norge gjort på 2. avdeling, Ullevål sykehus. Pasienten var en mann i 40-årene med levercirrhose, oesophagusvaricer og svær gastrointestinal blødning. Det var gjort transeksjon av ventrikkel og lagt ned Sengstaken-Blakemore-sonde. Han var i leverkoma da det på 3 . avdeling ble innlagt en mann med kritisk hodeskade. For ham var det ikke mulig med noen kurativ behandling, og man besluttet å skru av respiratoren. Han ble godtatt som donor av Aune og Frank Bergan (1909-1985), sjefen på 3. avdeling. Operasjonen varte i 545 minutter og var teknisk vanskelig, med betydelige blødningsproblemer. Leverresipienten døde kl 7 neste morgen.

Neste pasient var en kvinne i 40-årene som ble transplantert vinteren 1970. Hun hadde coloncancer med levermetastaser og ba selv om å bli levertransplantert. Hennes primærtumor var radikalt fjernet og det var ikke påvist metastaser utenom leveren, slik at en vellykket transplantasjon kunne teoretisk være kurativ. Første operasjon varte i 570 minutter. Hun ble så reoperert to ganger, relativt umiddelbart, med kolcystojejunostomi (210 minutter) og miltekstirpasjon (320 minutter). Til sammen ble hun operert i 1100 minutter; altså i nesten 21 timer. Jeg husker at vi holdt på i 35 timer, med de korte periodene pasienten var av bordet. Det var betydelige tekniske problemer med gallegangsanastomosen og med blødning. Snorre Aune var hovedoperatør hele tiden, med Gunnar Schistad, som tok ut lever, Morten Ræder og meg som assistenter. Dessverre er denne journalen borte, men fra operasjonsprotokollen går det frem at hun så ble reoperert omtrent to uker etter transplantasjonen (120 minutter) og så fem dager senere (160 minutter), begge gangene med Snorre Aune som operatør. Hun døde av en fulminant sepsis få dager etter denne siste operasjonen, 24 dager etter første operasjon. Tilfellet ble omtalt i en artikkel av Aune, Schistad og Skulberg der de diskuterte om denne pasienten skulle vært behandlet med azatioprin, «som tolereres dårlig av levertransplanterte», i stedet for kortikosteroider som eneste immunsuppressive behandling (10).

Den tredje levertransplantasjonen ble gjort sommeren 1972, rundt halvannet år etter den forrige. Pasienten var en mann i 60-årene med levercirrhose og oesopha- 
gusvaricer med blødning. Det var gjort transeksjon av ventrikkel, og pasienten var i leverkoma da han ble transplantert. Med på operasjonen var nå også Jan Stadaas (1934-2011). Operasjonen varte i 425 minutter og var ukomplisert. Pasienten våknet, var klar, kom ut av leverkoma, og den transplanterte leveren fungerte. Etter fire dager fikk han tegn på avstøtning og ble satt på deksametason $16 \mathrm{mg}$ daglig. Det skjedde et forbigående fall i transaminaser, men bilirubin, alkaliske fosfataser og gamma-GT fortsatte å stige. Deksametasondosen ble doblet og leverfunksjonen ble da tilfredsstillende, med serumverdier for albumin, fibrinogen, kolesterol og laktat/ pyrovat innenfor det normale. Pasienten var oppe i relativt god allmenntilstand og hadde god appetitt. Han utviklet imidlertid et svært duodenalsår som ga ham en plutselig fatal gastrointestinalblødning og han døde 53 døgn etter transplantasjonen. Ved obduksjon hadde den transplanterte leveren normalt utseende, blank speilende overflate og alle anastomoser intakte $(11,12)$.

\section{Fortsettelsen - eller mangelen på sådan}

Hvorfor sluttet så Snorre Aune og Gunnar Schistad med levertransplantasjoner? Hvordan reagerte det kirurgiske miljøet? Hva sa pressen og mediene om at man hadde transplantert de første levrene i Skandinavia? For å svare i omvendt rekkefølge: Det sto ikke ett ord om dette i noen norsk avis. Pressens interesse for det som foregikk på sykehusene var den gang minimal. Det kirurgiske miljøet så på det som eksperimentell kirurgi uten klinisk fremtid. Men Snorre Aune, Gunnar Schistad og Andreas Skulberg fikk Michael Skjelderups gullmedalje i 1971 for sitt pionerarbeid. Svaret på det første spørsmålet er i noen grad farget av de andre to svarene. I sin evaluering av levertransplantasjoner i 1982 nevner Thomas Starzl at det i perioden 1968-78 var kommet rapporter fra 11 andre sentre i verden med enkeltforsøk eller små serier. En av de siterte var rapporten til Aune, Schistad og Skulberg fra 1972 (5). Det var på det tidspunktet mindre enn 20 steder i verden som drev med organtransplantasjoner, og resultatene var dårlige.

Nyretransplantasjonsprogrammene på avdeling 3 på Ullevål og på kirurgisk avde- ling B, Rikshospitalet, der det ble gjort en serie transplantasjoner i tidsrommet 1963-83 med gode resultater, er et interessant unntak (13). Barnekirurgen Gunnar Schistad hadde en tanke om at levertransplantasjon var eneste behandling man kunne tilby barn født med galleveisatresi, som hadde $100 \%$ dødelighet. Men verken barnelegene eller nevrokirurgene ville gå inn på muligheten av å bruke barn som donor uansett tilstand. Man hadde på dette tidspunktet ikke innført begrepet hjernedød. Donor var derfor per definisjon i live, og man hadde i liten grad diskutert hvilke betingelser som måtte være oppfylt for å ta ut livsviktige organer når hjertet fortsatt slo (14). Det var først i 1973 at Norge, som det første land i Skandinavia, fikk en egen transplantasjonslov og innføring av begrepet hjernedød. Finland fikk imidlertid en slik lov i 1971. Avstøtning av transplantatet var videre et uoverstigelig hinder for at levertransplantasjon kunne ses på som noe man med god samvittighet kunne tilby sine pasienter. Jeg tror at Snorre Aune og Gunnar Schistad var for pasientrettet til å ville fortsette med denne eksperimentelle kirurgien som de nå beviselig hadde fått til rent teknisk.

Roy Calne arbeidet utrettelig for å finne et medikament mot avstøtning av transplantatet og fortsatte å transplantere. Det er han som har fătt mye av æren for utviklingen av ciklosporin, soppen fra Hardangervidda, som ble godkjent som medikament i 1982 og som revolusjonerte transplantasjonens historie (15). Med et slag gikk antall transplantasjonssentre i verden fra 20 til 1000 . Audun Flatmark tok opp levertransplantasjon med ortotopisk teknikk på Rikshospitalet i 1984 og satte transplantasjonene i system. Transplantasjonssenteret på Rikshospitalet har nå passert 1000 levertransplantasjoner. De første ti årene var ettårsoverlevelsen $63 \%$. I perioden $2005-08$ var den $92 \%$ (16).

Det var inspirerende for Morten Ræder og meg helt i begynnelsen av vår kirurgiske karriere å få være så nær to så begavede og dedikerte kirurger som Snorre Aune og Gunnar Schistad. De behersket hele det kirurgiske feltet og var i front av det som var kirurgisk nyskapning i verden. Mot mange odds brøytet de vei i et ulendt terreng, en vei som senere skulle vise seg å føre frem til vellykket behandling.

\section{Mons Lie (f. 1938)}

er spesialist i thoraxkirurgi og i karkirurgi og er pensjonist.

Forfatter har fylt ut ICMJE-skjemaet og oppgir ingen interessekonflikter.

Litteratur

1. Hume DM, Merrill JP, Miller BF et al. Experiences with renal homotransplantation in the human: report of nine cases. J Clin Invest 1955; 34 : 327-82.

2. Harrison JH, Merrill JP, Murray JE. Renal homotransplantation in identical twins. Surg Forum $1956 ; 6: 432-6$.

3. Thorsby E. Norsk transplantasjonsmedisin gjennom 50 år. Tidsskr Nor Lægeforen 2006; 126: 3305-10.

4. Starzl TE, Groth CG, Brettschneider L et al. Orthotopic homotransplantation of the human liver. Ann Surg 1968; 168: 392-415.

5. Starzl TE, Iwatsuki S, Van Thiel DH et al. Evolution of liver transplantation. Hepatology 1982; 2: 614-36.

6. Calne RY, Williams R. Liver transplantation in man. I. Observations on technique and organization in five cases. BMJ 1968; 4: 535-40.

7. Norman JC, Saravis CA, Brown ME et al. Immunochemical observations in clinical heterologous(Xenogenic) liver perfusions. Sugery 1966; 60: 179.

8. Flatmark A, Aune S, Otnes B et al. Heterolog leverperfusjon ved coma hepaticum. Tidsskr Nor Lægeforen 1969; 89: 809-13

9. Garnier H, Clot JP, Bertrand M et al. Liver transplantation in the pig: surgical approach. C R Acad Sci Hebd Seances Acad Sci D 1965; 260: 5621-3.

10. Aune S, Schistad G, Skulberg A. Human liver transplantation without azathioprine. Surg Gynecol Obstet 1972; 135: 727-8

11. Aune S. Orthotopic liver transplantation. Ann Chir Gynaecol Fenn 1973; 62: 175-7.

12. Aune S, Stadaas JO. Levertransplantasjon ved cirrhose. Tidsskr Nor Lægeforen 1976; 96: 497-9.

13. Gorlén T, Abdelnoor M, Enger E et al. Long term morbidity and mortality after kidney transplantation. Scand J Urol Nephrol 1992; 26: 397-401.

14. Bergentz S-E, Gelin L-E, Groth C-G et al. Dødskriteriet och transplantasjonskirurgien. Lækartidningen 1973; 70: 586 .

15. The official Dr. Thomas E. Starzl web site. www.starzl.pitt.edu/ (11.11.2015)

16. Foss A, Bergan A. Liver transplantation. I: Haffner J, Gerner T, Jacobsen A, red. Surgery in Norway. Oslo: Norwegian Surgical Society, 2011: 151-2.

17. Kåresen R. Digitale sykehushistorier. Ullevål museum - Medisinsk utvikling - Organtransplantasjon - Lever. http://sykehushistorier.no/ous/ index.php?museum=ulleval $\& 2=$ medisinsk $\& 3=$ organtransplantasjon (11.11.2015).

Mottatt 16.2. 2015, første revisjon innsendt 24.6 2015, godkjent 11.11. 2015. Redaktør: Sigurd Høye. 